\title{
CHALLENGES AND BENEFITS OF EXPERIENTIAL LEARNING: THE CASE OF OVERSEAS EXCHANGE PROGRAMS
}

\author{
Chieh Yun Yang, Dengming Xie (Corresponding author), Jose Weng Chou Wong \\ Macau University of Science and Technology \\ dengmingxie@outlook.com
}

\begin{abstract}
This article highlights an increasingly popular form of experiential learning, namely overseas exchange programs. Experiential learning is regarded as a valuable way to link up theoretical knowledge and practical skills in hospitality and tourism education. Although some studies have addressed the importance of experiential learning, the factors influencing students' choice of overseas exchange programs, and the challenges and benefits of students' experiential learning are still unclear, especially on the overseas exchange programs. The purpose of this study is to reveal the whole picture of overseas exchange programs by utilizing experiential learning cycle theory, and further understand students' perception of overseas experiential learning. By employing quantitative and qualitative methods, including questionnaire survey and in-depth interviews with students who have participated in the overseas exchange programs and content analysis of program information, this study analyzes the differences of factors considered by males and females in choosing overseas exchange programs, and displays the four-stage learning process of experiential learning in overseas exchange programs and identifies two themes of challenges (living challenges and learning challenges) and five themes of benefits (cognitive development, behavioural change, multiple skill development, social bonding development, academic competitiveness \& employability enhancement) for experiential learning for students majoring in Hospitality and Tourism. The study enriches our understandings of the experiential learning cycle theory and provides insights to educators in the design of future overseas exchange programs.
\end{abstract}

Keywords: experiential learning; challenges and benefits; overseas exchange programs; experiential learning cycle theory; hospitality and tourism education

\section{Introduction}

Hospitality and Tourism is an interdisciplinary subject that requires both theoretical knowledge and practical skills. Therefore, bridging the gap between theory and practice becomes crucial in hospitality and tourism education. Experiential learning approaches, such as field trips, role-playing, overseas studying, and so on, are considered effective ways to fill up the gap in the field of hospitality and tourism higher education. Among those approaches, the overseas exchange programs are regarded as an extension of experiential learning from the traditional classroom to a further field (Hopkins, 1999), and have become increasingly popular. According to the report published by the Institute of International Education (2020), as shown in Table 1, the number of non-degree international students in the United States has shown an overall growth trend in the past two decades. International exchanges programs (non-degree) can be divided into five levels according to the duration: several days to a few weeks; 3-8 weeks, summer programs; semester; semester to the academic year (this duration includes two levels) (Engle and Engle, 2003). There are obvious differences in specific learning contents and forms at different levels, including site (enterprise, museum, etc.) visits; "subject-matter" lectures and course; target-language course; international class; service-learning course; work internship, and so on (Coker et al. 2017; Engle and Engle, 2003). However, in the context of experiential learning, the studies to identify students' challenges and benefits in studying abroad programs are limited. To improve the overall quality of higher education, it is necessary to understand the value of such challenges and benefits created for students within the scope of humanities.

Kolb (1984) firstly developed the experiential learning cycle theory, and it has been widely applied in academic research and higher education practice. Researchers have reached a consensus that learning is a continuous process grounded in experience (Kolb, 1984; Kolb and Kolb, 2005). And experiential learning is the process of grasping and transforming knowledge to construct meaning from real-world experience (Kolb, 1984; Kolb and Kolb, 2017; Yardley et al., 2012). However, most existing literature ignored the grasping process and only paid attention to the transforming process directly when analyzing experiential learning projects (Yan and Cheung, 2012). In other words, previous studies focused on the gains of experiential learning for participants but did not analyze the challenges faced by participants in experiential learning programs. More specifically, the motivation and decision-making, the benefits and value of this kind of programs have received much attention (Bretag and van der Veen, 2017), but the questions of how participants adapt to the new circumstance and how study abroad programs impact participants' personal

(c) Chieh Yun Yang, Dengming Xie, Jose Weng Chou Wong. 2021. Published by Igor Sikorsky Kyiv Polytechnic Institute. This is an Open Access article distributed under the terms of the licence CC BY 4.0 
growth are still under investigation (Yu and Zhang, 2016). Therefore, it is important to understand what difficulties students face and how they ultimately resolve them.

Table 1. Number of international non-degree students in the United States (1999-2019)

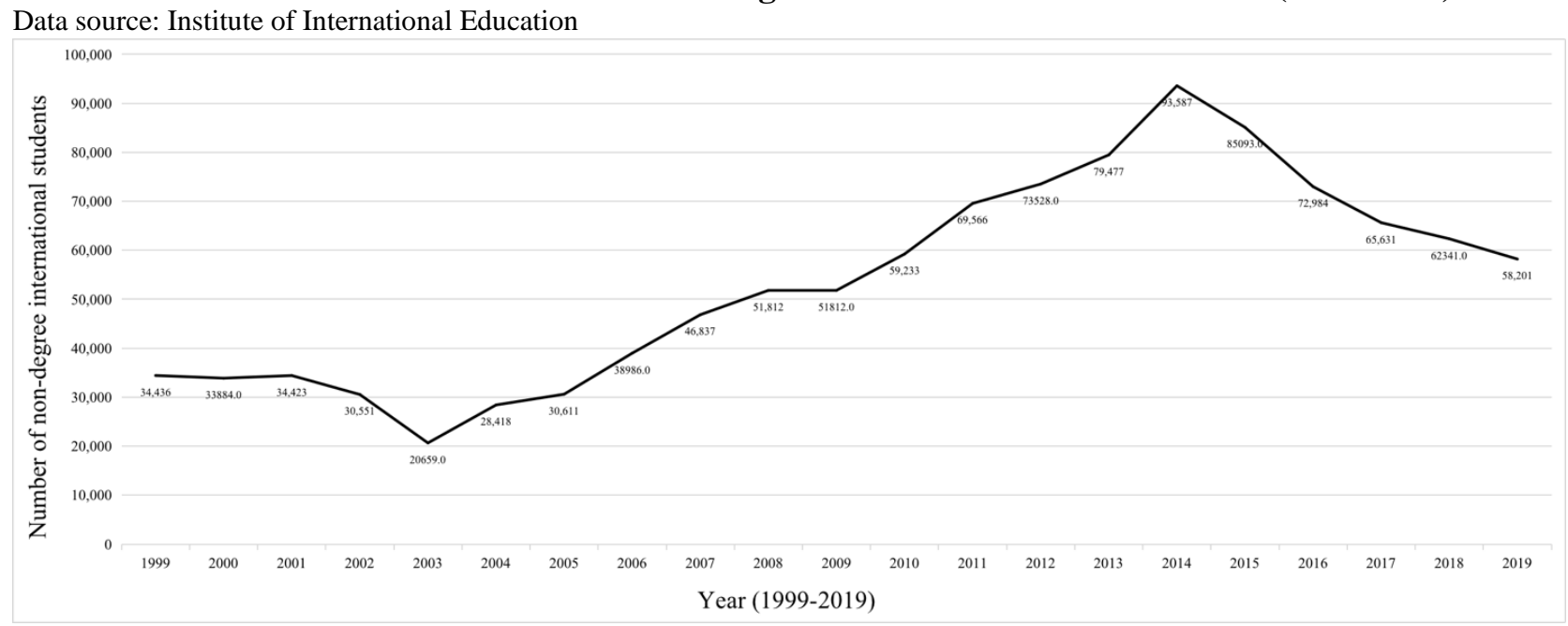

This study aims to reveal the whole process of overseas experiential learning and explore the challenges and benefits of overseas exchange programs in the field of hospitality and tourism. Fifteen students who had experience in such programs were invited to participate in this study. To understand their motivations and concerns for making decisions before the program, difficulties, and solutions during the program, gains after the program, they were asked to answer a series of open-ended questions through the indepth interview. The contribution of this study is twofold. First, applying experiential learning cycle theory, this study enriches the literature of grasping and transforming process by identifying students' challenges and benefits of study abroad programs. Second, the results of this study provide implications for education institutions (or program planners) to arrange experiential learning programs more effectively and give suggestions for participants (students) to choose appropriate experiential learning programs which are beneficial for their personal growth.

\section{Literature review}

Experiential learning theory

Kolb (1984) stated that learning is the process whereby knowledge is created through the transformation of experience; knowledge results from the combination of grasping and transforming experience. He further defined experiential learning as the process of grasping and transforming knowledge to construct meaning from real-world experience (Kolb, 1984, p.41). Based on Dewey, Lewin, and Piaget's learning model, Kolb (1984) analyzed the process of experiential learning and developed the experiential learning cycle theory (Figure 1), which includes four stages: concrete experience (CE), reflective observation (RO), abstract conceptualization (AC), and active experimentation (AE). These four stages are categorized as two primary dimensions of the learning process: the grasping dimension (CE \& AC) and the transforming dimension (RO \& AE). This reflects the two ways we learn. The first is how we perceive and grasp new information or experience, and the second is how we process and transform what we receive (Healey and Jenkins, 2000).

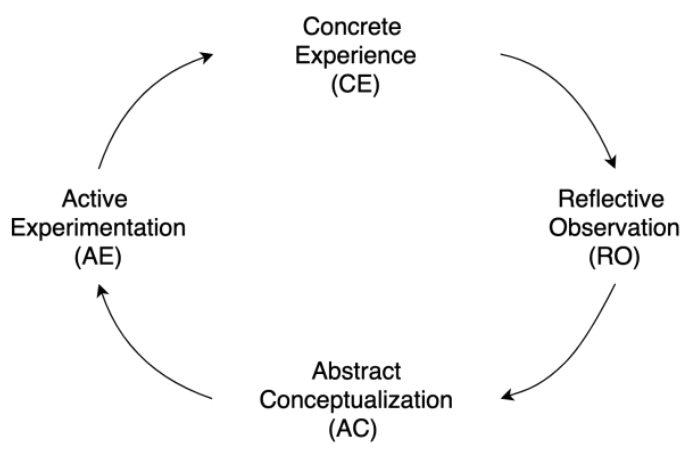

Figure 1. kolb's experiential learning cycle 
Challenges and benefits of studying abroad

Smith and Khawaja (2011) argued that international students who choose to study abroad might encounter many challenges, including acculturative stress and adaptation to the host country's environment. During the period of studying abroad, it is inevitable for international students to encounter a variety of challenges or difficulties caused by different circumstances (Gong et al., 2020). Based on the acculturation models, previous studies mentioned that language barriers, educational stressors, sociocultural stressors, discrimination, lifestyle acculturative stressors, and psychological challenges were the main challenges faced by international students (Pitts, 2016). For example, Yu and Zhang (2016) found that mainland Chinese students in Hong Kong experienced the challenges of language barriers, social interactions, political identification, and discrimination. Previous studies have recognized various challenges, but the findings of these research mainly relate to programs in the traditional classroom, rather than experiential learning programs, in which students may encounter different challenges.

Steinberg (2002) pointed out that overseas experiential learning is laudable and creditworthy, and identified the benefits of overseas experiential learning. For example, overseas experiential programs have strong academic value for students to gain linguistic skills, intercultural learning abilities, and analytical and conceptual skills. Numerous studies suggested that such programs offer a particularly valuable experience that cannot be substituted. This study agreed with the previous study that students on short-term (1-8 weeks) and long-term (typically a semester or longer) study abroad programs do show meaningful learning gains in developing intercultural sensitivity, global perspective, linguistic ability, lifelong friendships with hostcountry nationals (Coker et al., 2017). Although the benefits of various overseas experiential learning programs have been mentioned in previous studies, the findings may be different and deserve particular attention in different cultural contexts and different forms of programs.

\section{Methods}

Aiming to understand the process and outcomes of overseas experiential learning programs, this study adopted quantitative and qualitative methods to identify the key elements in whole experiential learning stages as suggested by Tsaur et al. (2019). A questionnaire survey with the theme of curriculum opinion survey was carried out to examine what factors students mainly considered when choosing international exchange programs. Also, the in-depth interview was conducted to collect data in a way that allowed the researchers to acquire detailed descriptions from the interviewees (DiCicco-Bloom and Crabtree, 2006).

\section{Study context and data collection}

Three overseas experiential learning programs in Macau Universities are involved in this study: New Zealand Wines Industrial Field Trip Program (13-days), U.S. International Hospitality \& Tourism Academic Program (3-weeks), and U.S. Disney Internship Program (6-months). The questionnaire data were borrowed from a curriculum opinion survey conducted by the institution with the consent of the students and the institution. The data were based on the 77 students' evaluation results of the importance (unimportant and important) of five consideration factors (program quality, program fee, previous participant evaluation, safety, difficulty of application process) in choosing the programs.

The interview data collection for this study has three steps: First, after obtaining the permission of the responsible education institution, the interview invitations were sent to 77 students who had attended one of the experiential learning programs. The invitation clearly stated the purpose and the voluntary principle of the interview and emphasized that all data are used for this research only and will not have any other impact on the interviewees. Students who were willing to participate in the interview were informed that all contents during the interview would be presented anonymously. Second, the in-depth interviews were conducted faceto-face in their native language. The interview guideline (See Appendix A) was inspired by previous studies (Yang et al., 2015) to understand students' experiences (challenges and benefits) in overseas experiential learning programs. Finally, the recorded interview transcripts were returned to all interviewees correspondingly for proofreading the contents. No incentives were provided in this study. A total of 15 students participated in the in-depth interview, remarking them N1 to N15. 3 respondents were male, and 12 respondents were female. The number of respondents in the three programs was 9,3 , and 3 , respectively. Overall, the interview took over 60 minutes on average, and the word count for the interview transcripts was more than 30,000 .

\section{Data analysis}

First, this study adopted SPSS 23.0 to perform a Chi-square test on the questionnaire data. Second, the text data were analyzed by deductive thematic analysis, which is to identify themes from qualitative data and 
answer the research questions (Xu et al., 2018). Deductive thematic analysis is a top-down method, which adopts the predetermined codebook based on literature. The code label, the definition of themes and, the descriptions of when the theme occurs are three critical elements involved in compiling the codebook (Xu et al., 2018). Two researchers in this study strictly followed the coding steps suggested by Fereday and MuirCochrane (2006) and work independently. Then, the final codes were identified after negotiation.

\section{Results of the Chi-square test}

Table 1 illustrates the results of the Chi-square test. The Chi-square test results show that there are significant differences between males and females on previous participants' evaluation and safety. In terms of the evaluation of the previous participants, $p$-value $=0.000<0.05$, indicating while the most female $(78.2 \%)$ think the previous participant's evaluation is important, male cares less about that (only 22.7\%). Regarding safety, $p$-value $=0.023<0.05$, indicating that males and females have significant differences in it. While most female $(72.7 \%)$ takes safety as an important factor to joining the international exchange program, more male (54.5\%) thinks that is not important. Besides, there are no significant gender differences in students' evaluation of program quality, program fee, and difficulty of the application process.

Table 1. The results of the Chi-square test

\begin{tabular}{|c|c|c|c|c|c|c|}
\hline \multirow{2}{*}{ Elements } & \multirow{2}{*}{ Option } & \multirow{2}{*}{$\begin{array}{c}\text { Count and expected } \\
\text { count }\end{array}$} & \multicolumn{2}{|c|}{ Gender } & \multirow{2}{*}{$X^{2}$} & \multirow{2}{*}{$P$} \\
\hline & & & Male & Female & & \\
\hline \multirow{4}{*}{$\begin{array}{l}\text { Program } \\
\text { quality }\end{array}$} & \multirow[t]{2}{*}{ Unimportant } & Count (\% within gender) & $8(36.4 \%)$ & $10(18.2 \%)$ & \multirow[t]{4}{*}{2.900} & \multirow[t]{4}{*}{0.089} \\
\hline & & Expected count & 5.1 & 12.9 & & \\
\hline & \multirow[t]{2}{*}{ Important } & Count (\% within gender) & $14(63.6 \%)$ & $45(81.8 \%)$ & & \\
\hline & & Expected count & 16.9 & 42.1 & & \\
\hline \multirow{4}{*}{$\begin{array}{l}\text { Program } \\
\text { fee }\end{array}$} & \multirow[t]{2}{*}{ Unimportant } & Count (\% within gender) & $7(31.8 \%)$ & $11(20.0 \%)$ & \multirow[t]{4}{*}{1.255} & \multirow[t]{4}{*}{0.268} \\
\hline & & Expected count & 5.1 & 12.9 & & \\
\hline & \multirow{2}{*}{ Important } & Count (\% within gender) & $15(68.2 \%)$ & $44(80.0 \%)$ & & \\
\hline & & Expected count & 16.9 & 42.1 & & \\
\hline \multirow{4}{*}{$\begin{array}{l}\text { Previous } \\
\text { participants' } \\
\text { evaluation }\end{array}$} & \multirow[t]{2}{*}{ Unimportant } & Count (\% within gender) & $17(77.3 \%)$ & $12(21.8 \%)$ & \multirow[t]{4}{*}{20.583} & \multirow{4}{*}{$\begin{array}{r}0.000 \\
(<0.05)\end{array}$} \\
\hline & & Expected count & 8.3 & 20.7 & & \\
\hline & \multirow[t]{2}{*}{ Important } & Count (\% within gender) & $5(22.7 \%)$ & $43(78.2 \%)$ & & \\
\hline & & Expected count & 13.7 & 34.3 & & \\
\hline \multirow[t]{4}{*}{ Safety } & \multirow[t]{2}{*}{ Unimportant } & Count (\% within gender) & $12(54.5 \%)$ & $15(27.3 \%)$ & \multirow[t]{4}{*}{5.133} & \multirow{4}{*}{$\begin{array}{c}0.023 \\
(<0.05)\end{array}$} \\
\hline & & Expected count & 7.7 & 19.3 & & \\
\hline & \multirow[t]{2}{*}{ Important } & Count (\% within gender) & $10(45.5 \%)$ & $40(72.7 \%)$ & & \\
\hline & & Expected count & 14.3 & 35.7 & & \\
\hline \multirow{4}{*}{$\begin{array}{l}\text { Difficulty } \\
\text { of } \\
\text { application } \\
\text { process }\end{array}$} & \multirow[t]{2}{*}{ Unimportant } & Count (\% within gender) & $11(50.0 \%)$ & $25(45.5 \%)$ & \multirow[t]{4}{*}{0.130} & \multirow[t]{4}{*}{0.718} \\
\hline & & Expected count & 10.3 & 25.7 & & \\
\hline & \multirow[t]{2}{*}{ Important } & Count (\% within gender) & $11(50.0 \%)$ & $30(54.5 \%)$ & & \\
\hline & & Expected count & 11.7 & 29.3 & & \\
\hline
\end{tabular}

\section{Results of thematic analysis}

Figure 2 shows the four-stage learning process of overseas exchange programs by utilizing the framework of experiential learning theory. The first element of concrete experience includes the experience of survival context and studying context. In this study, the experience of survival context includes clothing, food, house, and transportation, and so on. While the experience of studying context includes seminars, internships, field trips, role-play, and so on. And the reflection observation from the concrete experience includes mainly the living and learning challenges. On the other hand, existing studies have shown that cultural adaptation is regarded as one of the reasons students feel challenges when studying abroad (Gong et al., 2020). In response to these challenges, the participants adopted diverse strategic efforts to achieve personal development in various aspects: cognitive development, behavioural change, multiple skill development, social bonding development, academic competitiveness \& employability enhancement. 


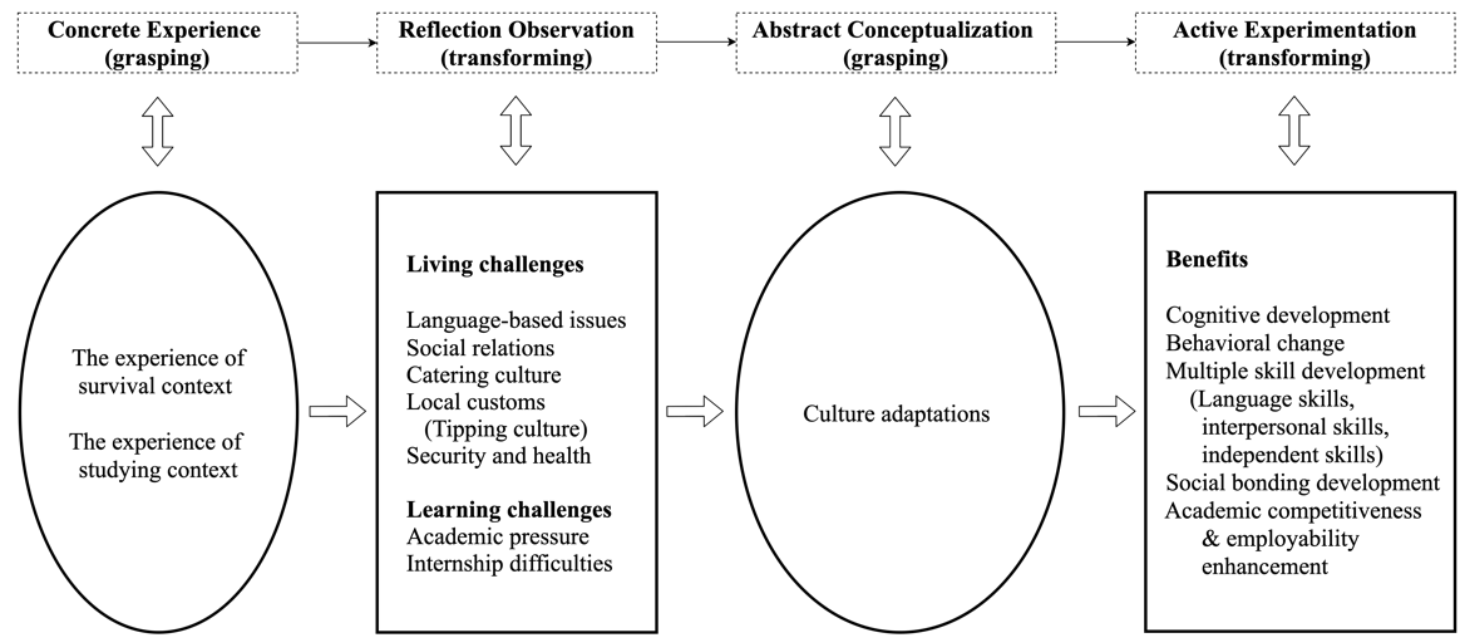

Figure 2. The four-stage learning processes of overseas exchange programs

Living challenge 1: language-based issues (12 of 15 interviewees addressed)

Language-based issues in overseas exchange programs include language barriers and different cultural expressions. Language barriers happen throughout their daily lives in all areas, such as restaurants, supermarkets, the library, and travelling. As N2 mentioned, "I have passed many English-related language exams, such as IELTS. But when I communicate with foreigners in person, some slangs, or expressions they often use are unfamiliar to me, and they become our big language barriers".

As people from different cultural backgrounds may have big differences in language expression, N4 and N14 expressed their embarrassment when they were praised in front of other students. For example, N4 stated, "Even if I made a low-level mistake in the day's work, my manager would still say to me, 'You did a good job today, you worked hard.' This makes me feel ashamed, but afterwards, I realized that good is not good enough. 'Good'means 90 points in our country but maybe it means 70 points here".

Living challenge 2: social relations (10 of 15 interviewees addressed)

When participants are joining the overseas exchange programs, everything around them is new and it makes some of them feel unfamiliar and difficult to make new friends. Although they need to contact local people, tourists, colleagues, and other participants in their daily life and work, it is still not easy for students to establish a friendship with other foreigners. "I am always thinking that people are treating me differently. Some people are caring for me too much, while some others are neglecting me. No matter what, I feel like I am an outsider, and I don't feel comfortable to make friends under this situation (N5, N9)".

Living challenge 3: local food culture (7 of 15 interviewees addressed)

The respondents who participated in the exchange program generally expressed that they had poor adaptability to the local food culture. Many interviewees (40\%) addressed that they tried hard to adapt to the local food and beverage, but they would get sick or even had negative physical reactions. "After coming here, I often eat high-calorie foods such as barbecues and hamburgers, and my weight has increased significantly in two months. There are not many food options here... (N8)". Many students (33\%) emphasized the ice water drinking habit in the U.S., while Chinese culture prefers warm or boiled water. As N3 said, "If we eat too much cold food, our body will become more susceptible to cold or humidity. But every time when I boiled water in the morning, my American roommates feel strange and surprised. It's really a cultural shock for them".

Living challenge 4: local customs (Tipping culture) (7 of 15 interviewees addressed)

In some Western countries, tipping is a recognition and thanks to the waitperson's hard work in a restaurant or hotel. However, it is not necessary for Chinese social culture, and half of the participants (50\%) felt not comfortable with the tipping culture, as N7 noted, "When I first started living in the United States, I don't have the sense to tip the waiters. Sometimes, the waiter will take the initiative to remind me if I forget to tip when I eat in the restaurant or take a taxi. Which made me very embarrassed, and then I gradually got used to it".

Living challenge 5: security and health (7 of 15 interviewees addressed)

In recent years, security has also become a big concern in overseas exchange programs. Two female participants said that for safety reasons, they generally do not walk alone outdoors (N3, N5). In addition, N7 
said, "It was more troublesome to see a doctor here. Besides language, we don't know the address of the hospital and the process of medical treatment, so I cannot go to the hospital alone. Sometimes I don't even know whom I should ask...". Some students (20\%) would therefore overlook their health issues, "The best solution to this question is not to get sick... (N5)".

Learning challenge 1: academic pressure (13 of 15 interviewees addressed)

A new foreign educational system different from hometown will put academic pressure on international students. Also, when students get used to traditional classroom teaching, the experiential learning model will also booster their challenges. Smith and Khawaja (2011) believed that this problem typically arose when international students attempt to adopt a new educational environment. In this study, the foreign cultural background and the form of experiential learning programs are new educational environments for most students. Therefore, academic pressure was one of the difficulties that participants can hardly avoid. "We have English lessons at my home university. In class, I can understand the teacher's words and sentences, but I can't understand the teaching logic very well. Instead of going out and writing a report, sometimes I prefer sitting in the classroom and writing an exam paper after the course (N13)".

Learning challenge 2: internship difficulties (5 of 15 interviewees addressed)

The difficulties from the internship include their language proficiency, lack of practical working experiences, and collaboration with colleagues. N7 mentioned that the internship work made her feel physically and psychologically exhausted. She even considered giving up the internship. N5 shared some comments, "During this internship, my mistakes sometimes lead to customer dissatisfaction, and it makes me very sad. I felt that I was bringing troubles to customers and colleagues rather than giving help".

Benefit 1: cognitive development (13 of 15 interviewees addressed)

Learning is a cognitive development linking persistent acclimatization with environmental engagement. The cognitive development through overseas experiential learning is mainly reflected in the perception of oneself (self-awareness and self-understanding), other people (social communication), and other things (international perspectives, cultural and global diversity, racial, ethnic diversity, and complexities of global issues) (Tian and $\mathrm{Lu}, 2018$ ). In the present study, respondents' self-rated improvement appears in selfconfidence, open-mindedness, independence, and self-reflection, and actualization. N6 believed that she has become braver than before, "I have met a lot of people during the internship, and they liked me very much. Now, I am more confident and dare to express my opinions positively". N12 was very excited to share with the interviewer the changes in his attitude towards life, "I like their (New Zealanders) attitude towards life. They usually spend lots of time staying with their families and preparing daily meals. I tried to experience the happiness of their lifestyle for a short time. After coming home, I began to pursue a higher level of quality of life instead of being busy with my goals".

Benefit 2: behavioural change (10 of 15 interviewees addressed)

Changes in actions are often affected by experience and environment, including voluntary or involuntary, temporary, or permanent changes. In this study, several participants $(27 \%)$ mentioned that the salary and expenditure in the programs lead to their behavioural changes, as N1 said, "Although I can get some salary every month, I must pay for the accommodation, meals, and many other fees. This is the first time I need to plan my incomes and expenses carefully in order not to exceed my living budget. I didn't work to earn money before but now I did know that earning money is not easy, and it changes my ways to consume".

Besides, several respondents (33\%) mentioned that overseas experiential learning experience has helped them change their habit of addiction to mobile and Internet. They were now more cherish the face-toface communication opportunities. Especially, N12 said, "During our stay in New Zealand, we spent most of our time in the tourism field, without Wi-Fi and mobiles. After a few days, we realized that we could live a good life without WIFI and mobiles; many calls or internet information may not be so important...".

Benefit 3: multiple skill development (10 of 15 interviewees addressed)

Participants in overseas exchange programs have seen obvious improved their language skills, interpersonal skills, and independent living skills. The skills development of participants is discussed and presented below.

Language skills. The improvement of language skills was shown in various aspects. Five interviewees from the short-term programs said, "I cherished the opportunity to make presentations in English during class. Even facing similar contents, all rounded English environment gave us different feelings, and we were forced to express ourselves in English (N13)." More than half of the interviewees (53\%) believed that they had become more proficient in English speaking, writing, reading, and listening, especially for taking TOEFL and IELTS tests.

Interpersonal skills. Previous studies have confirmed that study abroad programs can significantly 
improve students' ability to communicate with foreigners (Kurpis and Hunter, 2017). N2 realizes that people in western countries have more sense of privacy protection. Unless you take the initiative to talk about it, other people won't pry into your privacy or talk about things you don't want to reveal. Therefore, she noted, "I used to talk about anything with my friends and have no sense of boundaries. In the future, I will avoid interfering with friends' privacy issues, even if we are good friends".

Independent living skills. It is worth noting that many participants (53\%) reported that it is difficult for them to adapt to the local dietary habits. For short-term program members $(40 \%)$, they think this problem can be overcome. By contrast, long-term program members need to find an alternative way, such as cooking by themselves. N1 shared her experience of cooking during study abroad, "When I first tried cooking, I called with my mom and got the guidance of each step. Later, I was able to cook some simple daily dishes by myself, and I was delighted to learn cooking skills".

Benefit 4: social bonding development (7 of 15 interviewees addressed)

The social connections between people will be enhanced and closer as they spend more time staying together. In the process of adapting to the host society through direct and indirect contact with the local community, international students gradually developed social bonding with the community and residents (Gong et al., 2020; Tian and Lu, 2018). The concrete performance is to establish and maintain relationships with the people they meet. Five participants believed that they had developed their social bonds well with other participants from their alma mater, the host university, and universities of other countries. For example, participants can interact with other participants from different countries and local people, so that their social network has been further expanded. N5 mentioned it's fun to make friends with foreigners.

Benefit 5: academic competitiveness \& employability enhancement (5 of 15 interviewees addressed)

Previous studies have shown that enhancing the professional competitive advantage is one of the important factors to stimulate students to participate in overseas experiential learning programs (Mak et al., 2017), which includes academic competitiveness and employability enhancement. N4, N5, N7, N8, and N11 pointed out that overseas experiential learning experience is a bright spot on their resume because many enterprises prefer employees with the overseas learning experience. Besides, N11 believed that overseas internship experience has more tremendous advantages than domestic internship experience so that the candidates with overseas experience gain greater competitiveness. Both N6 and N15 said that the description of their applications for graduate school mainly focuses on their overseas experiential learning experience. N14 has finished applying for graduate school and claimed that "I attended an interview for a graduate school in the mainland of China. During my interview, almost all their concerns were on my overseas experiential learning experience".

\section{Discussion}

\section{Theoretical implications}

This study contributes to experiential learning cycle theory in the research of overseas exchange programs. Kolb (1984) firstly proposed this theory, which includes four stages named concrete experience, reflective observation, abstract conceptualization, and active experimentation. On this basis, this study integrated the challenges and benefits of studying abroad in previous research and further identified their antecedents and consequences. This paper is a pioneer study that comprehensively and systematically quested students' experiences of overseas experiential learning in the real survival and studying context. The results showcased the four-stage learning process of experiential learning in overseas exchange programs. Our works not only advance the conceptual definition of "culture adaptations" created by Gong et al. (2020), but also explain the mechanism of how it appears during study abroad and how does it in turn benefit students. Importantly, the four-stage learning process offers scholars a new perspective to understand international students' psychology and behaviorr performance. To this end, we believe that this research adds new nuances to the literature by displaying the four-stage learning process with the help of experiential learning cycle theory.

Moreover, compared with the results of previous studies, this study further detailed the challenges encountered by students and the benefits they gained during study abroad. In the present study, living challenges include language-based issues, social relations, catering culture, local customs (tipping culture), and security and health, and learning challenges include academic pressure and internship difficulties. Some of the results in this study are consistent with Tian and Lu's (2018) and Gong et al.'s (2020) study, while these new findings, such as security and health, and internship difficulties, are the unique perception of shortterm exchange students. Tian and $\mathrm{Lu}$ (2018) consider acculturation as international students' responses to such challenges. The process of overcoming these challenges is the time for students to grow. Studying abroad immerses participants in another cultural environment and creates new opportunities for them to 
improve their comprehensive capacities (Hopkins, 1999). The results indicated that benefits during study abroad include cognitive development, behavioural change, multiple skill development, social bonding development, academic competitiveness \& employability enhancement. These benefits are helpful for students majoring in Hospitality and Tourism to lay a good foundation for future development. Prior studies have focused on the benefits of international degree courses, whereas this study provides implications for the understanding of the benefits of international non-degree programs.

\section{Practical implications}

Since overseas experiential learning programs create many benefits for students' personal development, more international experiential learning opportunities should be provided for students by educational units. The cases utilized in this study show the challenges and benefits of overseas experiential learning programs. Based on the results of this study, program managers and students can evaluate the feasibility of the experiential learning programs. On one hand, for students who are going to enrol in non-degree programs, even degree courses, they can make a comprehensive consideration and plan for studying abroad according to the predictable challenges and benefits. On the other hand, managers can improve marketing management by including security measures and various emergency plans in the overseas experiential learning programs. Besides, according to the results of the Chi-square test, operators should pay more attention to improving the word-of-mouth generated by previous participants, and also safety issues as they are both important factors for female students to make decisions, especially there are more female students than male students in the hospitality and tourism field.

\section{Conclusion and limitation}

The experiential learning cycle theory is an effective tool for interpreting overseas experiential learning. In this study, qualitative methods were employed to explore students' experience process of overseas exchange programs. The results indicated that the challenges faced by students in the survival and studying context can be conceptualized as "cultural adaptation", which in turn helps students gain benefits in many ways. By understanding the potential difficulties and benefits in overseas experiential learning programs from students' perspectives, this study contributes to the teaching program design, marketing management, and preparation for studying abroad related to overseas experiential learning. The limitation of the study is that the survey was only conducted in universities in one city, which limits the universality of the findings to a certain extent. Also, this study only focused on short-term overseas experiential learning programs, and further research can consider both long-term international degree courses and short-term international exchange programs.

\section{Fund information}

The construction and implementation path of tourism education cooperation platform for countries along the Maritime Silk Road (No. hnjg2021ZD-4).

\section{References:}

Bretag, T., \& van der Veen, R. (2017). "Pushing the boundaries": Participant motivation and self-reported benefits of short-term international exchange programs. Innovations in Education and Teaching International, 54(3), 175-183. https://doi.org/10.1080/14703297.2015.1118397

Coker, J. S., Heiser, E., Taylor, L., \& Book, C. (2017). Impacts of experiential learning depth and breadth on student outcomes. Journal of Experiential Education, 40(1), 5-23. https://doi.org/10.1177/1053825916678265

DiCicco-Bloom, B., \& Crabtree, B. F. (2006). The qualitative research interview. Medical education, 40(4), $314-321$. https://doi.org/10.1111/j.1365-2929.2006.02418.x

Engle, L., \& Engle, J. (2003). Study abroad levels: Toward a classification of program types. Frontiers: The Interdisciplinary Journal of Study Abroad, 9(1), 1-20.

Fereday, J., \& Muir-Cochrane, E. (2006). Demonstrating rigor using thematic analysis: A hybrid approach of inductive and deductive coding and theme development. International journal of qualitative methods, 5(1), 80-92. https://doi.org/10.1177/160940690600500107

Gong, Y., Gao, X., Li, M., \& Lai, C. (2020). Cultural adaptation challenges and strategies during study abroad: New Zealand students in China. Language, Culture and Curriculum. https://doi.org/10.1080/07908318.2020.1856129

Healey, M., \& Jenkins, A. (2000). Kolb's experiential learning theory and its application in geography in higher education. Journal of geography, 99(5), 185-195. https://doi.org/10.1080/00221340008978967

Hopkins, J. R. (1999). Studying abroad as a form of experiential education. Liberal education, 85(3), 36-41.

Institute of International Education. (2020). "International Students by Academic Level, 1999/01-2019/20." Open Doors Report on International Educational Exchange. Retrieved from http://www.opendoorsdata.org

Kolb, D. A. (1984). Experiential learning: Experience as the source of learning and development. Englewood Cliffs, NJ: Prentice Hall.

Kolb, A. Y., \& Kolb, D. A. (2005). Learning styles and learning spaces: Enhancing experiential learning in higher education. 
Academy of management learning \& education, 4(2), 193-212. https://doi.org/10.5465/amle.2005.17268566

Kolb, A. Y., \& Kolb, D. A. (2017). Experiential learning theory as a guide for experiential educators in higher education. Experiential Learning \& Teaching in Higher Education, 1(1), 7-44. https://nsuworks.nova.edu/elthe/vol1/iss1/7

Kurpis, L. H., \& Hunter, J. (2017). Developing students' cultural intelligence through an experiential learning activity: A crosscultural consumer behavior interview. Journal of marketing education, 39(1), 30-46. https://doi.org/10.1177/0273475316653337

Mak, B., Lau, C., \& Wong, A. (2017). Effects of experiential learning on students: An ecotourism service-learning course. Journal of Teaching in Travel \& Tourism, 17(2), 85-100. https://doi.org/10.1080/15313220.2017.1285265

Pitts, M. J. (2016). Sojourner reentry: a grounded elaboration of the integrative theory of communication and cross-cultural adaptation. Communication Monographs, 83(4), 419-445. https://doi.org/10.1080/03637751.2015.1128557

Steinberg, M. (2002). "Involve Me and I Will Understand": Academic quality in experiential programs abroad. Frontiers: The Interdisciplinary Journal of Study Abroad, 8(1), 207-229. https://doi.org/10.36366/frontiers.v8i1.100

Smith, R. A., \& Khawaja, N. G. (2011). A review of the acculturation experiences of international students. International Journal of Intercultural Relations, 35(6), 699-713. https://doi.org/10.1016/j.ijintrel.2011.08.004

Tian, M., \& Lu, G. (2018). Intercultural learning, adaptation, and personal growth: A longitudinal investigation of international student experiences in China. Frontiers of Education in China, 13(1), 56-92. http://doi:10.1007/s11516-018-0003-3

Tsaur, S. H., Cheng, T. M., \& Hong, C. Y. (2019). Exploring tour member misbehavior in group package tours. Tourism Management, 71, 34-43. https://doi.org/10.1016/j.tourman.2018.09.018

Xu, J., Yan, L., \& Mak, C. K. (2018). Visitor experience of the Hong Kong trams as an unconventional attraction. International Journal of Tourism Research, 20(5), 605-612. https://doi.org/10.1002/jtr.2209

Yardley, S., Teunissen, P. W., \& Dornan, T. (2012). Experiential learning: transforming theory into practice. Medical teacher, 34(2), 161-164. https://doi.org/10.3109/0142159X.2012.643264

Yan, H., \& Cheung, C. (2012). What types of experiential learning activities can engage hospitality students in China. Journal of Hospitality \& Tourism Education, 24(2-3), 21-27. https://doi.org/10.1080/10963758.2012.10696666

Yang, H., Cheung, C., \& Fang, C. C. (2015). An empirical study of hospitality employability skills: perceptions of entry-level hotel staff in China. Journal of Hospitality \& Tourism Education, 27(4), 161-170. https://doi.org/10.1080/10963758.2015.1089510

Yu, B., \& Zhang, K. (2016). 'It's more foreign than a foreign country': Adaptation and experience of Mainland Chinese students in Hong Kong. Tertiary Education and Management, 22(4), 300-315. https://doi.org/10.1080/13583883.2016.1226944

Received: 26 August, 2021

Accepted:3 December, 2021 


\section{APPENDIX A--INTERVIEW GUIDELINE}

\begin{tabular}{|c|l|}
\hline Dimensions & \multicolumn{1}{|c|}{ Semi-structured questions } \\
\hline \multirow{2}{*}{ Motives } & $\begin{array}{l}\text { What motives you to choose experiential learning programs? } \\
\text { What motives you to choose overseas programs instead of local ones? }\end{array}$ \\
\hline \multirow{5}{*}{ Scruples } & $\begin{array}{l}\text { During your decision-making process, do you have any barriers? If yes, what influence } \\
\text { you most, and why? }\end{array}$ \\
\hline \multirow{5}{*}{ Challenges } & $\begin{array}{l}\text { Would you please tell you one story of your biggest challenges during your experiential } \\
\text { learning period? } \\
\text { How did you solve/overcome them? }\end{array}$ \\
\cline { 2 - 3 } & $\begin{array}{l}\text { What kinds of support did you get from the faculty staff? } \\
\text { What is the role of the leader of the experiential learning trip? }\end{array}$ \\
\hline \multirow{5}{*}{ Benefits } & $\begin{array}{l}\text { What are the biggest effects of your experience in the experiential learning program on } \\
\text { your future career? }\end{array}$ \\
\cline { 2 - 3 } & $\begin{array}{l}\text { Did you think your life get changed after the experiential learning program? If yes, how? } \\
\text { What are the positive effects of your experience in experiential learning on the rest of } \\
\text { your undergraduate study? }\end{array}$ \\
\cline { 2 - 3 } & $\begin{array}{l}\text { What cultural differences did you perceive when you started your overseas experiential } \\
\text { learning? What did you learn from them? }\end{array}$ \\
\cline { 2 - 3 } & $\begin{array}{l}\text { Does your experiential learning change your communication skills? If so, in which } \\
\text { aspects and how did the changes happen? }\end{array}$ \\
\cline { 2 - 3 } & $\begin{array}{l}\text { Does your experiential learning change your interpersonal skills? If so, in which aspects } \\
\text { and how did the changes happen? }\end{array}$ \\
\hline
\end{tabular}

